\title{
Seroprevalence of IgG Antibodies against Mumps in Bulgarian Children under 18 Years of Age
}

\author{
Milena Karcheva, Galya Gancheva
}

Department of Infectious Diseases, Epidemiology, Parasitology and Tropical Medicine, Pleven Medical University, Pleven, Bulgaria

\begin{abstract}
Objective: The objective of this study was to determine the prevalence of $\operatorname{lgG}$ antibodies against mumps in a representative stratified sample of children under 18 years of age in Pleven district, Bulgaria.

Study Design: Cross sectional study.

Materials and Methods: A cross-sectional, sero-epidemiologic survey of 132 children aged under 18 years was conducted in Pleven district. They were distributed into two age groups: from 0 to 11 years old $(n=80)$ and from 12 to 18 years old $(n=52)$. An enzyme immunoassay (ElA) was performed for indirect evidence of specific lgG antibodies in the serum.

Results: The results showed that $41 \%$ of the investigated children were negative in terms of mumps lgG antibodies, $11 \%$ had borderline values and the remaining, approximately $48 \%$, were positive. In the group of children aged 0 to 11 years who had received one dose of the mumps vaccine, $50 \%$ were negative for mumps IgG antibodies. In the second group of children aged 12 to 18 years who had received two vaccine doses, the percentage of participants negative for mumps $\lg \mathrm{G}$ antibodies decreased significantly.
\end{abstract}

Conclusion: Our observations emphasise the need to conduct expanded sero-epidemiological investigations of the populations most affected by mumps and to immunise susceptible individuals.

Key Words: Mumps, seroprevalence, immunisation.

Received: 15.06.2012

Accepted: 31.10 .2012

\section{Introduction}

Reducing the rise of epidemic mumps at a global scale became possible due to large-scale specific immunoprophylactics. In 2008, there were 193 member countries and two associated countries in the World Health Organisation (WHO), distributed in six regions. Vaccination against mumps is applied in 114 (59\%) countries in America, Europe and the Western Pacific region. In 104 (91\%) of them, the combined measles, mumps and rubella (MMR) vaccine is used as part of their national immunisation scheme. The occurrence of epidemic outbreaks in countries with wide vaccination programs demonstrates the need for discussion on vaccine immunity, schemes of immunisations and applied vaccine preparations $(1,2)$. The determination of levels of antibody against vaccine-preventable diseases is significant in evaluating the status of herd immunity and immunisation programs. Theoretically, the level of antibodies, requiring interruption, the transfer of mumps virus is between $85 \%$ and $90 \%$ for all age group, excluding children under 10 years of age. Surveys on outbreaks show differences in mumps antibody concentrations of between 15 and $90 \%$, depending on age, sex, immunisation programs in certain countries and the type of mumps vaccine strain (3-6). The objective of this study was to determine the prevalence of mumps $\lg G$ antibodies in a representative stratified sample of children under the age of 18 years in Pleven district, Bulgaria.

\section{Materials and Methods}

A cross-sectional sero-epidemiologic survey was conducted on 132 children under the age of 18 years in Pleven district. The participants in the survey were recruited randomly in a stratified sample after giving informed consent. A questionnaire was used to obtain information on sex, age and immunisation status regarding mumps. Exclusion criteria were: suspected mumps, a history of past mumps, transfusion of blood products and MMR immunisation in the last six months preceding sera collection. The study included 132 children, distributed into two age groups: from 0 to 11 years and from 12 to 18 years. The criterion for the separation was due to the immunisation scheme: immunisation at 13 months of age and re-immunisation at 12 years of age (this scheme was introduced in 2000 in Bulgaria).

Enzyme immunoassays (EIA) were applied to indirectly determine levels of mumps IgG antibodies in the serum. The 
EIAs were performed according to the instructions of the manufacturer Orgenium Laboratories (Finland). Mumps lgG kit Antibody EIA75 was used, designed for semi-quantitative determination of mumps lgG antibodies in serum. The data were analysed using the Statgraphics Plus Version 2.1. package. We used Kolmogorov-Smirnov test (K-S test) for non-parametric distributions; $p<0.05$ was considered to be significant.

\section{Results}

The analysis of sex distribution showed that 52 (39\%) of the participants were boys and $80(61 \%)$ girls. The immunisation status of the children is shown in Table 1 . The children in the age group 0-11 years had been immunised with one dose of the MMR vaccine (100\%), while those in the second age group had been immunised with two doses of the MMR vaccine (88\%).

The results of the serological investigations for mumps $\lg G$ antibodies are shown in Table 2.

We observed differences in the distribution of sero-prevalence in the children in the two age groups (shown in Figures 1 and 2). Half of the children in the first age group were negative $(50 \%), 45 \%$ positive ( $p>0.05)$, and $5 \%$ displayed borderline results. The children in this group had received only one dose of the vaccine. In the second age group, the prevalence of children negative for the mumps antibody decreased to $27 \%$ and those positive increased to $54 \%(p<0.05)$. Ten children $(19 \%)$ had borderline results because statistical evaluation was not available for a few of the children. The group with negative results included children immunised with the monovaccine, as well as those with one and two doses of the MMR vaccine. The group with borderline results contained children who had received two doses of the vaccine.

The distribution of mumps IgG antibodies depending on sex is shown in Figures 3 and 4. The prevalence of positive

Table 1. Immunization status of the tested children

\begin{tabular}{|lccc|}
\hline $\begin{array}{l}\text { Age group } \\
1 \text { dose of the } \\
\text { MMR vaccine }\end{array}$ & monovaccine & $\begin{array}{c}\text { Applied vaccine, } \mathrm{n}(\%) \\
\text { 2 doses of the } \\
\text { MMR vaccine }\end{array}$ \\
\hline $0-11$ & $80(100 \%)$ & - & - \\
$12-18$ & $2(4 \%)$ & $4(8 \%)$ & $46(88 \%)$ \\
MMR: Measles, mumps and rubella & & \\
\hline
\end{tabular}

Table 2. Seroprevalence of mumps-specific lgG antibodies in the tested children

\begin{tabular}{|lccc|}
\hline $\begin{array}{l}\text { Benchmarks } \\
\text { (s/co ratio) }\end{array}$ & Results & $\begin{array}{c}\text { Number (n) } \\
\text { /Ratio (\%) }\end{array}$ & Interpretation \\
\hline$<0.8$ & $\begin{array}{c}0.006-0.798 \\
(\bar{x}=0.412, \text { sd=0.25) }\end{array}$ & $54(41 \%)$ & Negative \\
$0.8-0.99$ & $\begin{array}{c}0.829-0.956 \\
(\bar{x}=0.870, \text { sd }=0.04)\end{array}$ & $14(11 \%)$ & Borderline \\
& $\begin{array}{l}0.999-3.538 \\
(-4\end{array}$ & $64(48 \%)$ & Positive \\
& $(\bar{x}=1.842$, sd=0.63) & & \\
\hline
\end{tabular}

Seroprevalence of mumps-specific IgG antibodies in age group 0-11

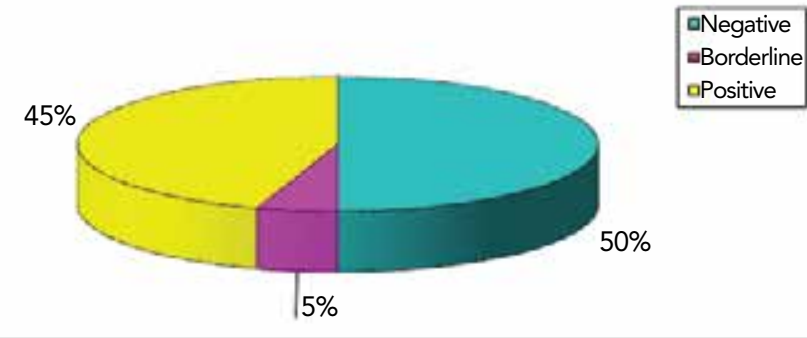

Figure 1. Seroprevalence of mumps-specific lgG antibodies in the age group 0-11

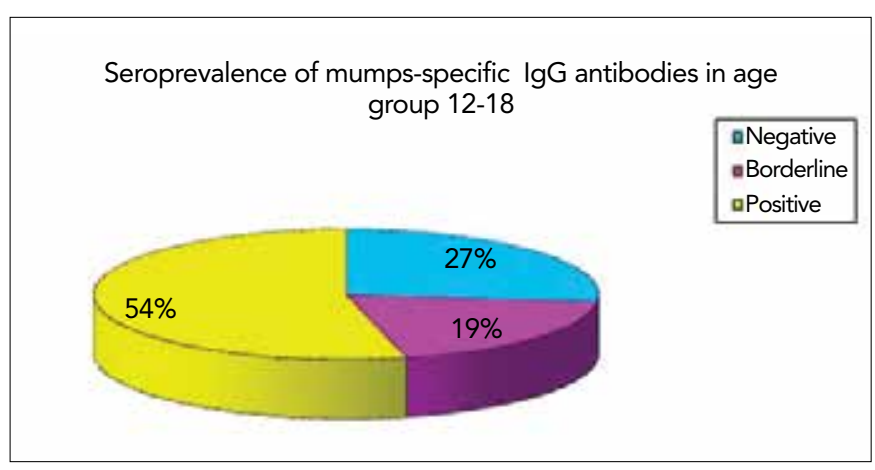

Figure 2. Seroprevalence of mumps-specific lgG antibodies in the age group 12-18

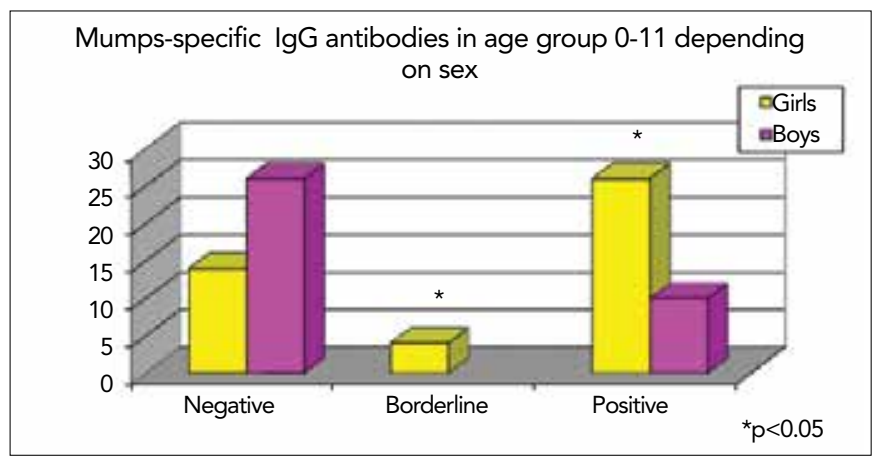

Figure 3. Seroprevalence of mumps-specific IgG antibodies in the age group 0-11 depending on sex

Mumps-specific lgG antibodies in age group 12-18 depending

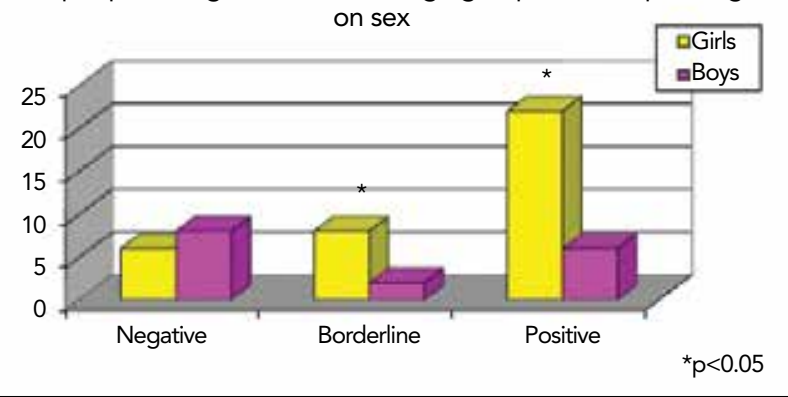

Figure 4. Seroprevalence of mumps-specific lgG antibodies in the age group 12-18 depending on sex 
girls was significantly higher in the two age groups compared to positive boys (in the first age group, $\mathrm{KST}=1.62, \mathrm{p}<0.05$, and in second, $\mathrm{KST}=2.54, \mathrm{p}<0.05$ ).

\section{Discussion}

Our results were reported and interpreted according to the instructions of the manufacturer of the test in the context of epidemiological information. All the investigated children had been immunised under the immunisation scheme of the country. The results showed a lack of sufficient immunity against mumps needed to avoid epidemiological outbreaks of the disease. The global prevalence of antibodies was $48 \%$ for mumps. Other studies have found higher prevalence rates of mumps antibodies in different European countries $(3,6,7)$. As seen from our results, a significant number of the children (41\%) are at risk of contracting mumps. There are age differences in the prevalence of mumps antibodies (3, 7-9). Half of the children aged 0 to 11 years (50\%) were negative for mumps IgG antibodies (Figure 1). According to the data of other authors, newborns in their first month after delivery possess high passive immunity acquired from their mothers. However, this immunity decreases 6 to 9 months after birth. The different seroprevalence of mumps antibodies is due to the different terms of administration of the vaccine in different countries (4). A trend of waning immunity has been observed between the first and second vaccine doses (10). It is obvious that the immunity of immunised children decreases within years after the first dose of vaccine. It is therefore appropriate to re-immunise children at the age of 5 to 6 years, as performed in most European countries, the USA, Israel and others $(1,11)$. For the second age group, 12 to 18 years, the prevalence of children negative for mumps lgG antibodies decreased $(27 \%)$, that is, the prevalence of those positive for the antibodies was higher in this age group. This is likely to be due to the second dose of the vaccine applied and/or encounter with the wild mumps virus, which has a booster effect on the immunity of the population. Our data correlate with those of other authors, who also determined more children positive for the mumps antibody at an older age $(3,5,7,12)$. Their results were related to the booster effect of circulating wild mumps viruses, given that their investigations used only one dose of vaccine. In some of the abovementioned investigations, increases of antibody presence from 20 to $98 \%$ of the population were seen, with the higher rates recorded for older age groups $(5,13)$.

Our study did not reveal a difference in the impact of the mumps virus on gender. Other authors have not established differences in the presence of antibodies regarding sex $(5,11)$. However, our data revealed a significantly higher prevalence of mumps antibodies in girls $(p<0.05)$. Similar results were found by another study examining the presence of mumps IgG antibodies in children aged 1 to 5 years, 10 to 13 years and 14 to 17 years (11). There are few studies about the distribution of mumps lgG antibodies with regards to sex (11).

Our observations show the necessity to conduct expanded sero-epidemiological investigations of the populations most affected by mumps and to immunise susceptible individuals. It is necessary to increase the vaccine coverage and herd immunity to decrease epidemic distribution of the disease. The worldwide discussion concerning usage of highly efficient live vaccines has not ended yet. Our modest investigations confirm the need to increase the number of immunisations, which is confirmed by the epidemiological practice over the last two decades.

Ethics Committee Approval: Ethics committee approval was received for this study.

Informed Consent: Written informed consent was obtained from patients who participated in this study.

Peer-review: Externally peer-reviewed.

Author contributions: Concept - M.K.; Design - M.K.; Resource M.K.; Materials - M.K.; Data Collection\&/or Processing - M.K.; Analysis\&/or Interpretation - G.G.; Literature Search - G.G.; Writing - M.K.; Critical Reviews - G.G.

Conflict of Interest: No conflict of interest was declared by the authors.

Financial Disclosure: No financial disclosure was declared by the authors.

\section{References}

1. Karcheva M. Survey on efficiency of mass specific immune prophylactics at mumps. Summary of Dissertation. 2010;1-65.

2. Amanna IJ, Nichole EC, Mark KS. Duration of humoral immunity to common viral and vaccine antigens. N Engl J Med 2007;357:1903-15. [CrossRef]

3. Dominguez A, Plans P, Costa J, Torner N, Cardenosa N, Batalla J, et al. Seroprevalence of measles, rubella, and mumps antibodies in Catalonia, Spain:results of a cross-sectional study. Eur J Clin Microbiol Infect Dis 2006;25:310-7. [CrossRef]

4. Desgrandchamps D, Schaad UB, Glaus J, Tusch G, Heininger U. Seroprevalence of $\lg G$ antibodies against measles, mumps and rubella in Swiss children during the first 16 months of life. Schweizerische Medizinische Wochenschrift 2000;130:1479-86.

5. Gürgöze MK, Yilmaz E, Gödekmerdan A, Akça Z, Doğan Y, Akarsu $\mathrm{S}$, et al. Seroprevalence of mumps, varicella and rubella antibodies in children 1-16 years of age in eastern Turkey. Turk J Pediatr 2006;483:185-8.

6. Sáenz González MC, Núñez Mateos JC, Rodrigo Sánchez N, Martín Sánchez AM. Sero-epidemiologic study of measles, rubella and mumps in the infantile population of Salamanca. An Esp Pediatr 1992;36:293-7.

7. Socan M, Berginc N. High seroprevalence of varicella, measles, mumps, rubella and pertussis antibodies in first-grade medical students. Wien Klin Wochenschr 2008;120:422-6. [CrossRef]

8. Odiseev $\mathrm{H}$. Specific immuno prophylactics of mumps with live vaccine-strain, Sofia 6. Summary of Dissertation 1970;1-74.

9. Odiseev H. Surveys on mumps in Bulgaria. Summary of Dissertation 1976;1-76.

10. Eriksen J, Davidkin I, Kafatos G, Andrews N, Barbara C, Cohen D, et al. Seroepidemiology of mumps in Europe (1996-2008):why do outbreaks occur in highly vaccinated populations? Epidemiol Infect 2012;12:1-16.

11. Muhsen Kh, Aboudy Y, Mendelson E, Green MS, Cohen D. Prevalence of mumps antibodies in the Israeli population in relation to mumps vaccination policy and incidence of disease. Epidemiol Infect 2008;136:688-93. [CrossRef]

12. Stohrer-Draxl P, Amstad H, Grize L, Gassner M, Takken-Sahli K, Bourquin $C$, et al. Measles, mumps and rubella:vaccination rate and seroprevalence in 8th grade students of 8 different sites in Switzerland 1995/96. Schweiz Runsch Med Prax 1999;88:1069-77.

13. Zäch K, Nicoara C, Germann D, Matter L. Age-related seroprevalence of measles, mumps and rubella antibodies in 1996. Schweiz Med Wochenschr 1998;128:649-57. 